\title{
Markets as beneficial constraints on the government*
}

\author{
Alberto Bisin ${ }^{\dagger}$ \\ New York University \\ Adriano A. Rampini ${ }^{\ddagger}$ \\ Northwestern University \\ First Draft: December 2003 \\ This Draft: April 2005 \\ Forthcoming, Journal of Public Economics
}

\begin{abstract}
We study the role of anonymous markets in which trades cannot be monitored by the government. We adopt a Mirrlees approach to analyze economies in which agents have private information and a benevolent government controls optimal redistributive tax policy. While unrestricted access to anonymous markets reduces the set of policy instruments available to the government, it also limits the scope of inefficient redistributive policies when the government lacks commitment. Indeed, the restrictions that anonymous markets impose on the optimal fiscal policy, especially on capital taxation and the history-dependence of income taxation, can have positive welfare effects in this case.
\end{abstract}

JEL classification: E61; H21; D82

Keywords: Markets; Optimal policy; Optimal taxation; Time consistency

${ }^{*}$ We thank V.V. Chari, Dean Corbae, Andrea Eisfeldt, Michael Fishman, Mikhail Golosov, Olivier Jeanne, John Ledyard, Edward Prescott, Emmanuel Saez, the co-editor, and two anonymous referees for very helpful comments. We also thank seminar participants at the 2003 Society of Economic Dynamics Annual Meeting, Northwestern University, the Federal Reserve Bank of Minneapolis, the University of Texas at Austin, and Duke University (Fuqua). This paper was previously circulated under the title "Anonymous Markets and Optimal Policy."

${ }^{\dagger}$ Corresponding author: Department of Economics, New York University, 269 Mercer Street, New York, NY, 10003. Phone: (212) 998-8916. Fax: (212) 995-4186. Email: alberto.bisin@nyu.edu.

‡Department of Finance, Kellogg School of Management, Northwestern University, 2001 Sheridan Road, Evanston, IL, 60208. Email: rampini@northwestern.edu. 


\section{Introduction}

Consider an economy in which agents have private information, for example, about their income. A benevolent government controls redistributive tax policy. Should the government in such an environment always collect the private information from the agents to inform its policy decisions? Do anonymity and anonymous competitive markets have an essential role in this environment? Or are they simply "constraints" on the decision problem of the government?

These questions can be readily answered in the context of the theory of optimal fiscal policy where taxes are designed to implement the optimal allocation of a mechanism design problem. In this context, when a government has full commitment, any possible policy decision can be supported by a mechanism which induces the agents to reveal their information to the government truthfully. This is an implication of the Revelation Principle. ${ }^{1}$ Moreover, anonymous markets are in fact constraints on the decision problem of the government, because they make it more difficult for the government to extract the information from the agents truthfully. In other words, the free access to anonymous markets ex-post restricts the set of incentive compatible allocations from which the government chooses ex-ante, and hence restricts policy decisions. $^{2}$

But consider instead an economy in which the government lacks commitment regarding its policy decisions and therefore has to face the issue of time inconsistency, in the sense of Kydland and Prescott (1977). In this environment anonymity and anonymous markets are no longer simply "constraints" on the decision problem of the government. The optimal redistribution policy of a benevolent government without commitment illustrates this point. Such a government cannot commit not to exploit all the information in its possession, e.g., information contained in previous tax reports or information about an agent's assets, to redistribute resources across the agents in the economy. Such an ex-post redistribution policy might have ex-ante welfare costs for a benevolent government. This is the case, for instance, if it reduces the agents' ex-ante incentives to exert effort in their production activities, or if it distorts agents' consumption-savings decisions. Giving agents access to anonymous markets may limit the information that the government has ex-post and thus may limit the time-inconsistency problem. Thus, giving agents additional choices in the form of unrestricted access to anonymous capital markets may be optimal despite the fact that it might add additional agency problems in taxation. This is an implication of the fact that, when a government lacks commitment, optimal taxes may still be

\footnotetext{
${ }^{1}$ See Myerson (1979) and Harris and Townsend (1981) among others.

${ }^{2} \mathrm{~A}$ sizeable literature has developed which characterizes the inefficiency of environments in which agents are not restricted to exclusive contractual relationships with the principal, but have access to outside anonymous markets; see Arnott and Stiglitz (1983), Allen (1985), Hammond (1987), which is aptly titled "Markets as Constraints," Fudenberg, Holmström, and Milgrom (1990), Bisin and Gottardi (1999), Cole and Kocherlakota (2001), Bisin and Rampini (2006), Golosov and Tsyvinski (2003a,b), and many others.
} 
chosen to implement the optimal allocation of a mechanism design problem; but it is not in general sufficient to restrict the analysis to direct revelation mechanisms, which induce the agents to reveal their private information to the principal truthfully, and non-revealing mechanisms must be considered. In other words, while a version of the Revelation Principle holds without commitment, its implication and significance need to be reconsidered. ${ }^{3}$

We adopt a Mirrlees approach to the study of optimal fiscal policy in several simple economies with private information, including economies with hidden effort, hidden income, and hidden productivity (as in Mirrlees, 1971). In contrast to the Ramsey approach to taxation, therefore, we do not impose any ex-ante assumptions on the class of tax schemes considered. Optimal tax schemes are instead those which implement the consumption and savings allocation which solves the optimal mechanism design problem of the economy. In contrast to most of the literature on Mirrlees taxation, e.g., Kocherlakota (2004a,b), we extend the analysis to the case of economies in which the government cannot commit.

We show that in all our two-period economies, both when the government has commitment and when it does not have commitment, it is sufficient to consider tax schemes composed of $i$ ) an income tax in the initial period; ii) a history-dependent income tax (or a social security payment, depending on sign and interpretation) in the second period; and iii) a tax on capital, possibly a non-linear function of capital. As shown by Golosov, Kocherlakota, and Tsyvinski (2003) in a related environment, when the government has commitment, a wedge between the agents' and the social shadow interest rate needs to be imposed to implement the optimal consumption and savings allocation. Nonetheless, effective taxes on capital, the taxes that agents pay in equilibrium, may optimally be set to zero in our economy. In fact, the wedge in shadow interest rates can be implemented by imposing a positive marginal tax rate on capital only for savings exceeding the optimal amount. In other words, the optimal savings allocation can be implemented by a non-differentiable tax scheme such that agents will effectively face zero taxes on capital. ${ }^{4}$ Moreover, with commitment, income taxes are set in the initial period, independently of the agents' savings choices. When the government lacks commitment, on the other hand, it chooses income taxes for the second period ex-post and ends up making income taxes depend on the agents' past savings decisions. This specific form of historydependence is the crucial effect of lack of commitment and of time inconsistency: the government cannot commit not to redistribute the agents' accumulated savings across agents ex-post to provide social insurance; that is, the government cannot commit not to expropriate agents who save and not to bail out agents who do not save expost. Therefore, agents' savings decisions are inefficiently distorted. Indeed, because of its incentive to redistribute savings ex-post in the second period, the government needs to design a tax system in the initial period which induces agents to save. A

\footnotetext{
${ }^{3}$ See the discussion in Section 2.

${ }^{4}$ See also Kocherlakota $(2004 \mathrm{a}, \mathrm{b})$.
} 
savings subsidy in the second period, for instance, would not do, since it would be undone by the government ex-post in the second period, e.g., by means-testing of social security payments.

In this context it then follows that granting the agents unrestricted access to anonymous credit markets restricts the set of possible tax schemes that the government can impose. In particular, it renders those tax schemes infeasible which distort the representative agent's savings decision, and which the government might otherwise impose in the second period. On the other hand, granting access to anonymous credit markets also limits the ability of fiscal policy to redistribute resources across agents ex-post and thus limits the provision of social insurance. Anonymous markets may therefore be welfare improving for a benevolent government without commitment, notably for economies in which the welfare costs of reduced social insurance are smaller than the welfare benefits which can be obtained by eliminating the distortions on savings. Anonymous markets may also be welfare improving when a government without commitment would otherwise provide so much social insurance that agents would no longer have an incentive to exert effort. We show that it is particularly the restrictions that anonymous markets impose on capital tax schedules, and on the history-dependence of income tax schedules, that have potentially positive welfare effects when the government lacks commitment. We also show that unrestricted access to anonymous capital markets may be essential to implementing optimal allocations, in the sense that agents will trade in these markets in equilibrium.

While our analysis of the welfare effects of providing access to anonymous financial markets is developed in the context of several simple example economies with hidden income, hidden effort, and hidden productivity, we believe our results have important policy implications.

First, our analysis can be interpreted as providing a normative and positive rationale for offshore financial markets. Consistent with our analysis, the growth of offshore banking markets can be traced to restrictive fiscal and regulatory regimes in many European countries in the 1960s and 1970s. More recently, even though regulatory distortions in developed countries have substantially declined, offshore centers thrive as a mechanism for individual investors to avoid precisely those redistributive fiscal policies that are the focus of our analysis of lack of commitment, e.g., inheritance and other capital taxes. ${ }^{5,6}$

Most importantly, our analysis of the welfare effects of anonymous credit markets helps better understand the effects of international capital mobility. Many authors have discussed the possibility that capital mobility might have negative welfare ef-

\footnotetext{
${ }^{5}$ See, e.g., IMF Background Paper (2000).

${ }^{6}$ Perhaps the clearest example of the role of unmonitored anonymous financial markets which had an important role in limiting the amount of redistributional taxation, thereby favoring investment and capital accumulation, is the case of Swiss bank accounts used by Italian investors.
} 
fects by limiting the ability of governments to implement desired fiscal policies. ${ }^{7}$ For instance, a large literature on tax competition (see Fuest, Huber, and Mintz, 1993, for a survey) has stressed the possibility of "tax-base flight" and "tax exportation." Similarly, DeLong (2004) notices that recent instances of liberalization of international capital markets (e.g., NAFTA) have generated substantial flows of capital from developing to developed countries, and that this has severely limited the scope of redistributive fiscal policy in developing countries. Our analysis offers a different interpretation of such capital flows and a different evaluation of their welfare effects. In fact, developing countries are often plagued by corruption and poor governance of political and, in particular, fiscal policy institutions. In this context, capital mobility indeed limits their ability to enforce redistribution and social insurance policies, but in turn might provide these countries with better investment incentives by constraining inefficient capital taxation. Naturally, such a positive effect of capital mobility is only possible in economic environments where governance is not so poor that the protection of basic property rights is not guaranteed and hence markets cannot operate freely and efficiently. We interpret the cross-country evidence that capital mobility has positive effects on growth and that this effect is severely reduced for countries at very early stages of development (see Edwards, 2001) as consistent with our analysis. ${ }^{8}$

It is not our intent to claim that capital mobility and offshore markets necessarily have positive welfare effects. Clearly, offshore markets may also serve various illegal and even criminal purposes, such as money laundering. Also, capital mobility might lead to the substantial under-provision of public goods. ${ }^{9}$ Nor is this a paper on the globalization of international capital markets or on offshore financial markets. Rather, we show by way of examples that unmonitored anonymous markets (including international and offshore financial markets) may serve the important purpose of limiting the distortionary redistributive tax policies that even benevolent governments, whenever lacking commitment, would adopt. In other words, we propose this as a new rationale for why anonymous markets improve economic efficiency.

\section{Optimal fiscal policy without commitment: A Mirrlees approach}

In this paper we study optimal redistributive fiscal policy without commitment in simple two-period asymmetric information economies. Rather than attempting a

\footnotetext{
${ }^{7}$ Of course capital mobility has also other important consequences through channels unrelated to fiscal policy; for instance, it integrates investment opportunities, but it may induce inefficient financial crisis; see for instance Hausmann and Velasco (2004); see also Gourinchas and Jeanne (2004) for a calibration exercise documenting small welfare effects due to these channels.

${ }^{8} \mathrm{~A}$ related argument in the non-academic literature is in Friedman (1999).

${ }^{9}$ See, e.g., Huber (1999) for a theoretical analysis of optimal fiscal policy with commitment in a two-country economy which delivers this result.
} 
general analysis of the optimal taxation problem, we study several examples that illustrate our main result, namely that anonymous markets can be welfare improving when the government lacks commitment, even if the government is benevolent. ${ }^{10}$ All examples we study are economies with two periods populated by ex-ante identical agents. Agents receive stochastic income realized in the first period and have private information either about their income, their effort, or their productivity (as in Mirrlees, 1971). ${ }^{11}$

In each of these economies the government chooses a tax policy in the first period to maximize the representative agent's ex-ante expected utility. Lacking commitment, though, the government will choose a new tax policy in the second period using all the information it has available, which includes the information collected during the enforcement of the tax policy in the first period. The ability to condition tax policy in the second period on the information collected through fiscal policy in the first period gives rise to a time-inconsistency problem. This formulation of the period 2 objective of a government without commitment essentially imposes sub-game perfection on the equilibrium of the optimal taxation game as, e.g., in Kydland and Prescott (1977). It is common in the optimal contract literature to require instead a notion of renegotiation-proofness in which agents cannot commit to allocations which are Pareto dominated ex-post. Renegotiation-proofness does not constrain the class of problems we study in this paper, however, since in our context lack of commitment implies ex-post incentives to redistribute resources across agents, which is welfare improving ex-post but not a Pareto improvement.

We follow a Mirrlees approach to dynamic optimal taxation and we envision optimal policy as a solution to a mechanism design problem; see Mirrlees (1971). Recent contributions to optimal dynamic taxation have favored this approach over Ramsey's; see Albanesi and Sleet (2004), Golosov, Kocherlakota, and Tsyvinski (2003), Golosov and Tsyvinski (2003a,b), and Kocherlakota (2004a,b). These papers, as Mirrlees' original contribution, study optimal taxation in economies in which the government has full commitment. We are instead interested in the analysis of economies in which the government lacks commitment. In this case, the set of allocations that the government can implement through fiscal policy must satisfy the requirements of time consistency. ${ }^{12}$ As a consequence, new methodological issues arise regarding the Mirrlees approach to optimal taxation and in particular the identification of optimal policy through the solution to a mechanism design problem. ${ }^{13}$

\footnotetext{
${ }^{10}$ Of course, when the government is not benevolent it is easier to construct examples in which anonymous markets, which limit the set of policy instruments available to the government, are welfare improving.

${ }^{11} \mathrm{We}$ also compute a numerical example for an economy in which both the agents' income and their effort choice are private information; see Section 4.1 .

${ }^{12}$ In our finite horizon setting there is no room for reputational mechanisms as studied, e.g., by Stokey $(1989,2003)$ and Chari and Kehoe (1990).

${ }^{13}$ A Mirrlees approach to optimal taxation has rarely been adopted to study economies in which
} 
More specifically, a Mirrlees approach to optimal fiscal policy involves first characterizing the optimal incentive compatible consumption and savings allocation as the solution to a mechanism design problem and then solving explicitly for a tax scheme which implements the optimal consumption and savings allocation. However, when the government lacks commitment the mechanism design problem is complicated by the fact that it is not in general sufficient to restrict the analysis to direct revelation mechanisms, which induce the agents to reveal their private information to the principal truthfully. Direct revelation mechanisms, in fact, might not implement all incentive compatible allocations when the government lacks commitment, and hence they might not implement all allocations induced by some indirect tax policy. Without commitment, the government cannot commit not to exploit the information, which it has collected, in the future. It might then be optimal for the government not to induce the agents to reveal their private income realizations, that is, not to rely on a direct revelation mechanism inducing truth-telling. This has been recognized in the literature and a version of the Revelation Principle has been derived for economies without commitment by Bester and Strausz $(2001,2003) .{ }^{14}$

For the environments analyzed in this paper, this version of the Revelation Principle implies that the set of all allocations that can be induced by some tax policy coincides with the set of all allocations implemented by direct truth-telling mechanisms augmented by those allocations which can be implemented by non-revealing mechanisms. In particular, randomization in reporting strategies will turn out not to be optimal. When studying optimal fiscal policy without commitment we therefore proceed as follows: i) we first characterize the optimal allocation in the class of direct revelation mechanisms, that is, under truth-telling; ii) we then characterize the optimal allocation when we allow for non-revealing mechanisms; iii) we finally solve for a system of taxes which implements the optimal allocation overall, be it revealing or not.

In all the examples we study the maximization problem of the government, with or without commitment, leads to a unique optimal allocation in terms of agents' consumption. This is not the case, of course, for the corresponding tax implementation problems: many tax schemes in general implement a unique optimal allocation. We show that in our economy it is sufficient to consider tax schemes composed of $i$ ) an income tax in the first period; ii) an income tax (or a social security payment,

the government lacks commitment. An early study is Roberts (1984); recently, see Berliant and Ledyard (2003).

${ }^{14}$ See, e.g., Freixas, Guesnerie, and Tirole (1985) and Laffont and Tirole (1988) for examples of the failure of the standard Revelation Principle as, e.g., in Myerson (1979) in economies without commitment. The classical example in this literature is one of a monopolist repeatedly facing a buyer whose valuation for an object is private information but constant over time; see Skreta (2002) for a clear exposition. 
depending on sign and interpretation) in the second period; and iii) a tax on capital in the second period, possibly a non-linear function of capital.

\section{Optimal fiscal policy with hidden income}

Consider the following economy with 2 periods, i.e., 3 dates, and a continuum of ex-ante identical agents. Agents have preferences represented by

$$
\sum_{t=1}^{2} \beta^{t-1} u\left(c_{t}\right)
$$

where $c_{t}$ is the consumption of the single consumption good at time $t$, and $u\left(c_{t}\right)$ is a strictly increasing and strictly concave utility function. Agents receive a stochastic time 1 income, $\theta_{1}$, taking either value $\theta_{1 H}$ or $\theta_{1 L}, \theta_{1 H}>\theta_{1 L}$, with exogenous probability $\pi_{H}$ and $\pi_{L}$, respectively. Income shocks are independent and identically distributed across agents. Agents receive no income at time 2. We therefore interpret time 2 as the retirement age. We assume that agents can borrow and lend at the interest rate factor $R=\frac{1}{\beta}$.

While we are interested in the optimal policy without commitment, we consider the case in which the government has commitment as a benchmark. ${ }^{15}$

\subsection{Optimal fiscal policy with commitment}

We will first characterize the optimal consumption allocation of this economy, that is, we formulate and solve the mechanism design problem. Since we assume here that the government has commitment, we can restrict the mechanism design problem without loss of generality to the class of direct revelation mechanisms. At time 0 , the government chooses a state contingent consumption allocation, $\left(c_{1 s}, c_{2 s}\right)_{s=H, L}$, to maximize the ex-ante expected utility of the agents

$$
\sum_{t=1}^{2} \beta^{t-1} \sum_{s=H, L} \pi_{s} u\left(c_{t s}\right)
$$

subject to the incentive compatibility constraint

$$
u\left(c_{1 H}\right)+\beta u\left(c_{2 H}\right) \geq u\left(c_{1 L}+\theta_{1 H}-\theta_{1 L}\right)+\beta u\left(c_{2 L}\right)
$$

and the government's budget constraint

$$
\sum_{s=H, L} \pi_{s} c_{1 s}+\frac{1}{R} \sum_{s=H, L} \pi_{s} c_{2 s} \leq \sum_{s=H, L} \pi_{s} \theta_{1 s} .
$$

\footnotetext{
${ }^{15}$ Kocherlakota (2004b) studies the optimal fiscal policy problem with commitment in a related economy.
} 
The second incentive compatibility constraint, requiring truth-telling by type $\theta_{1 L}$, has been dropped since it is not binding.

It is straightforward to show the following:

Proposition 1 At the optimal allocation with commitment: i) agents with high income realization consume more in both periods: $c_{1 H}=c_{2 H}>c_{1 L}>c_{2 L}$; ii) agents are provided with partial social insurance, that is, resources are transferred to agents with the low income $\theta_{1 L}$, and they consume more than the present value of their income: $c_{1 L}-\theta_{1 L}+\frac{1}{R} c_{2 L}>0>c_{1 H}-\theta_{1 H}+\frac{1}{R} c_{2 H}$; and iii) agents save different amounts at time 1 and agents with high income save more: $k_{L} \equiv \frac{1}{R} c_{2 L}<k_{H} \equiv \frac{1}{R} c_{2 H} \cdot{ }^{16}$

How can the optimal allocation be implemented via a tax system? As noted above, the optimal allocation can be implemented with the following fiscal policy instruments: an income tax at time $1, t_{1 s}$, an income tax (or a social security payment, depending on sign and interpretation) at time $2, t_{2 s}$, and a tax on capital, $\mathcal{T}_{s}$, possibly a non-linear function of capital. ${ }^{17}$ In particular, agents with low income can be induced to save the optimal amount by levying appropriate taxes on savings. While in this economy income shocks are not publicly observable, the government may however observe and tax the agents' savings, $k_{s}$, at time 2 , for $s=H, L$.

Let the effective tax on capital be the tax that agents pay at the optimal allocation, that is, for an agent of type $s$ the value of the map $\mathcal{T}_{s}$ at the optimal savings $k_{s}$ that taxes implement. Our implementation result is as follows:

Proposition 2 The optimal allocation with commitment can be implemented with an income tax at time $1, t_{1 s}$, history-dependent social security payment at time 2 , $-t_{2 s}$, and a tax on capital, $\mathcal{T}_{s}$, a piecewise linear function of $k_{s}$, at time $2, s=H, L$. Optimal taxes can be designed so that: i) the tax on capital for high income agents, as well as the effective tax on capital for low income agents, are zero; and ii) the present value of the taxes of high income agents is positive while the present value of the taxes of low income agents is negative: $t_{1 H}+\frac{1}{R} t_{2 H}>0>t_{1 L}+\frac{1}{R} t_{2 L}$.

We proceed in the following to prove Proposition 2 and in turn to characterize the optimal taxes $\left(t_{1 s}, t_{2 s}, \mathcal{T}_{s}\right)_{s=H, L}$ which implement the optimal allocation. Optimal

\footnotetext{
${ }^{16}$ The marginal return on saving at the optimal allocation is higher for low income agents than for high income agents. As in Kocherlakota (2004b) incentive compatibility introduces a wedge between the subjective shadow interest rate of the agents, in our case of the agents with low income, and the social shadow interest rate.

${ }^{17}$ Note that we allow taxes to depend on the income realization $s$ (or $\theta_{1 s}$, which is equivalent) at time 1 or on the agents' announcements thereof, even though income may not be observable to the government. Our formulation is therefore different from Mirrlees' and most of the ensuing literature, in which incentive compatibility is obtained through non-linear tax schemes which are allowed to depend only on observables. It is however equivalent, and it allows for a simpler analysis, especially when formulating the optimal policy problem without commitment. Berliant and Ledyard (2003) also use a mechanism design formulation in a related environment.
} 
taxes solve the following problem. An agent with income shock $\theta_{1 s}, s=H, L$, takes the tax scheme $\left(t_{1 s}, t_{2 s}, \mathcal{T}_{s}\right)_{s=H, L}$ as given and faces the following problem at time 1 :

$$
\max _{\left(k_{s}, c_{1 s}, c_{2 s}, \hat{s}\right)} \sum_{t=1}^{2} \beta^{t-1} u\left(c_{t s}\right)
$$

subject to

$$
c_{1 s}=\theta_{1 s}-t_{1 \hat{s}}-k_{s}, \quad c_{2 s}=R k_{s}-\mathcal{T}_{\hat{s}}\left(k_{s}\right)-t_{2 \hat{s}},
$$

where $\hat{s} \in\{H, L\}$. The tax system $\left(t_{1 \hat{s}}, t_{2 \hat{s}}, \mathcal{T}_{\hat{s}}\right)$ which the agent faces depends on the income, that is, the state $\hat{s}$, which he declares. The government's policy problem is to choose $\left(t_{1 s}, t_{2 s}, \mathcal{T}_{s}\right)_{s=H, L}$ to maximize the ex-ante expected utility of the representative agent,

$$
\sum_{t=1}^{2} \beta^{t-1} \sum_{s=H, L} \pi_{s} u\left(c_{t s}\right),
$$

subject to the constraint that $\left(k_{s}, c_{1 s}, c_{2 s}, s\right)$ solves the agent's problem (4-5) given $\left(t_{1 s}, t_{2 s}, \mathcal{T}_{s}\right)_{s=H, L}$, for $s=H, L$, and the government's budget constraint

$$
\sum_{s=H, L} \pi_{s} t_{1 s}+\frac{1}{R}\left(\sum_{s=H, L} \pi_{s}\left(t_{2 s}+\mathcal{T}_{s}\left(k_{s}\right)\right)\right)=0 .
$$

We first characterize the optimal taxes on capital $\mathcal{T}_{s}$, which support the optimal allocation and in particular support optimal savings, $k_{s}=\frac{1}{R} c_{2 s}, s=H, L$. We let $\mathcal{T}_{s}$ depend on $s$ and $k_{s}$, i.e., we allow for taxes on capital which are a history-dependent function of savings. Take an agent with income $\theta_{1 s}$. Define the capital tax rate $\mathcal{T}_{s}^{\prime}$ by setting $\mathcal{T}_{s}^{\prime}(k)=\tau_{s}^{+}$if $k>k_{s}$ and $\mathcal{T}_{s}^{\prime}(k)=\tau_{s}^{-}$otherwise. The first order condition with respect to $k_{s}$ of an agent who declares type $s$ is

$$
u^{\prime}\left(c_{2 s}\right)\left(1-\tau_{s}^{+}\right) \leq u^{\prime}\left(c_{1 s}\right) \leq u^{\prime}\left(c_{2 s}\right)\left(1-\tau_{s}^{-}\right)
$$

and hence, rearranging,

$$
\tau_{s}^{-} \leq 1-\frac{u^{\prime}\left(c_{1 s}\right)}{u^{\prime}\left(c_{2 s}\right)} \leq \tau_{s}^{+}
$$

If $\tau_{s}^{+}$and $\tau_{s}^{-}, s=H, L$, are chosen to satisfy these inequalities, then agents who announce their income truthfully, i.e., choose the tax schedule designed for their income, will indeed save $k_{s}$. Given the characterization of the optimal allocation in Proposition 1, we see that (9) can be satisfied by setting $\tau_{s}^{-}=0, s=H, L$. But ensuring that agents cannot do better by choosing a different tax schedule and saving more or less imposes additional constraints on the tax schedule $\tau_{s}$. In the Appendix we provide a detailed analysis of optimal taxes on capital, and we show that, without loss of generality, the optimal allocation can be implemented with $\tau_{L}^{-}=\tau_{H}^{-}=0$. We say therefore that effective taxes on capital are zero, in the sense that even though 
a positive marginal tax rate, $\tau_{L}^{+}>0$ for $k>k_{L}$, is necessary to implement the optimal allocation, agents with income $\theta_{1 s}$ will in equilibrium save $k_{s}$, and face a tax on capital $\tau_{s}^{-}$which is zero independently of their income realization. In the Appendix we show furthermore that we can implement the optimal allocation with zero taxes on capital for the agents who declare high income at time 1 , that is, with $\tau_{H}^{+}=\tau_{H}^{-}=0$. Agents declaring a low income at time 1 must instead face a positive tax on capital if they save more than at the optimal allocation, i.e., $\tau_{L}^{+}>0$. This is required to induce agents with low income to save optimally and to induce agents with high income to report their income to the government truthfully. ${ }^{18}$

The optimal income tax at time $1, t_{1 s}$, and the optimal social security payment at time $2, t_{2 s}$, are then determined to support the optimal consumption allocations $c_{1 s}$ and $c_{2 s}: t_{1 s}=\theta_{1 s}-k_{s}-c_{1 s}$ and $t_{2 s}=R k_{s}-\mathcal{T}_{s}\left(k_{s}\right)-c_{2 s}$. Note that the condition $t_{2 s}=R k_{s}-\mathcal{T}_{s}\left(k_{s}\right)-c_{2 s}$ is an equilibrium condition; each agent, after having revealed his type $s$, considers the social security payment $t_{2 s}$ as lump-sum and in particular as independent of his savings choice $k_{s}$.

\subsection{Optimal fiscal policy without commitment}

We will first characterize the optimal consumption allocation of this economy by studying the mechanism design problem. Since we assume here that the government does not have commitment, as we noted in the previous section, we first look at direct revelation mechanisms which induce truth-telling and then at non-revealing mechanisms. We finally study the properties of the tax schemes which implement the optimal allocation.

The optimal fiscal policy without commitment under truth-telling must satisfy the constraint that the policy be optimal at time 2, after the agents' types have been revealed. Formally, we need to require that the allocation $\left(c_{2 H}, c_{2 L}\right)$ which the government promises to agents at time 1 satisfies

$$
\left(c_{2 H}, c_{2 L}\right) \in \arg \max _{\hat{c}_{2 H}, \hat{c}_{2 L}} \sum_{s=H, L} \pi_{s} u\left(\hat{c}_{2 s}\right) \text { subject to } \sum_{s=H, L} \pi_{s} \hat{c}_{2 s} \leq \sum_{s=H, L} \pi_{s} c_{2 s} .
$$

Thus, $\left(c_{2 H}, c_{2 L}\right)$ has to solve the problem of the government at time $2 .{ }^{19}$ Otherwise, the problem is the same as the problem in (1-3). Constraint (10) implies that the government cannot commit not to provide full insurance across agents' types at time 2: $c_{2 H}=c_{2 L}$. This in turn implies that the incentive compatibility constraint (2) requires $c_{1 H}=c_{1 L}+\theta_{1 H}-\theta_{1 L}$; that is, no social insurance: $c_{1 s}+\frac{1}{R} c_{2 s}=\theta_{1 s}, s=H, L$.

We next show that non-revealing mechanisms (and, hence, randomized reporting strategies) cannot improve on the representative agent's welfare in this economy. A

\footnotetext{
${ }^{18}$ In other words, $\tau_{L}^{+}>0$ is required to implement the wedge between the shadow interest rate of agents who declare low income and the social shadow interest rate at the optimal allocation; see footnote 16 .

${ }^{19}$ We can interpret the government which solves the time 2 problem as the time 2 government and will at times refer to it in that way.
} 
non-revealing mechanism requires that agents receive type-independent transfers at time 1 and at time 2. Moreover, agents cannot alter their allocation by choosing a different savings level since savings are observable, and hence in any non-revealing mechanism the allocation has to satisfy $c_{1 H}-c_{1 L}=\theta_{1 H}-\theta_{1 L}$ and $c_{2 H}-c_{2 L}=0$. We conclude that in this economy the set of allocations in the class of non-revealing mechanisms is smaller than the set of allocations in the class of direct revelation mechanisms (but it contains the optimal allocation).

We have therefore shown the following:

Proposition 3 At the optimal allocation without commitment: i) agents are fully insured at time 2: $c_{2 H}=c_{2 L}$; but ii) agents do not perfectly smooth their consumption: $c_{1 s} \neq c_{2 s}, s=H, L$; and iii) agents are provided with no social insurance: $c_{1 s}+\frac{1}{R} c_{2 s}=$ $\theta_{1 s}, s=H, L$.

Consider now the implementation problem of the optimal allocation without commitment via a tax system composed of income taxes $t_{1 s}$ and $t_{2 s}$, and a tax on capital, $\mathcal{T}_{s}$. Several aspects of tax schemes when the government lacks commitment are worth noting. First, while a government with commitment can equivalently impose a tax on capital either in the first or in the second period, a government which lacks commitment needs to impose its tax on capital in the first period, since the government would otherwise undo the tax in the second period. ${ }^{20}$ Second, the tax on capital $\mathcal{T}_{s}$ is only available to the government if savings are observable. Third, the possible dependence of taxes $t_{2 s}$ at time 2 on $s$ is a form of history-dependence of the tax scheme. It might however be optimal for the government at time 1 to implement a tax scheme which is independent of $s$ at time 1 in order to make it impossible for the government at time 2 to design history-dependent taxes. This is the case when the optimal allocation is induced by a non-revealing mechanism.

We can show the following implementation result for our economy:

Proposition 4 The optimal allocation without commitment can be implemented by a truth-telling tax scheme consisting of an income tax at time $1, t_{1 s}$, a history-dependent social security payment at time $2,-t_{2 s}$, and a tax on capital or a savings subsidy, $\mathcal{T}_{s}$, a piecewise linear function of $k_{s}$, at time $1, s=H, L$. Optimal taxes are designed such that: i) savings below $k_{s}$ trigger taxes equal to the shortfall (or, alternatively, imply an equivalent loss in subsidies); and ii) social security payments $t_{2 s}$ are chosen by the government at time 2 as an increasing function of $k_{s}$ to provide full insurance ex-post, $s=H, L$.

Note that this implementation scheme, different from the scheme used with commitment in Proposition 2, requires that taxes on capital be imposed at time 1 . This is an important consequence of lack of commitment, as will be shown in the following.

\footnotetext{
${ }^{20}$ In the tax implementation we consider, we assume for simplicity that the tax on capital is chosen by the time 1 government, but this is without loss of generality in terms of the optimal allocation.
} 
Let taxes on capital be piecewise linear, i.e., $\mathcal{T}_{s}^{\prime}(k)=\tau_{s}^{-}$for $k \leq k_{s}$ and $\mathcal{T}_{s}^{\prime}(k)=\tau_{s}^{+}$ otherwise. As noted, because of lack of commitment on the part of the government, we need in principle to distinguish between truth-telling schemes, which allow for revealing income taxes at time $1, t_{1 H} \neq t_{1 L}$ and $\mathcal{T}_{H} \neq \mathcal{T}_{L}$, and non-revealing schemes which require $t_{1 H}=t_{1 L}$ and $\mathcal{T}_{H}=\mathcal{T}_{L}$. In either case, the optimal consumption allocation without commitment satisfies $k_{H}=\frac{1}{R} c_{2 H}=\frac{1}{R} c_{2 L}=k_{L}$, and hence need not induce different savings for different types of agents. Non-revealing tax schemes cannot improve on truth-telling schemes. While this follows from the characterization of the optimal allocation in Proposition 3, it is instructive to reinterpret this result in terms of the tax implementation problem. Even if the tax scheme at time 1 is non-revealing, the government could still choose a redistributive tax scheme, $t_{2 H} \neq$ $t_{2 L}$, to provide full insurance, whenever agents save different amounts, $k_{H} \neq k_{L}$. Thus, because of the observability of savings, both types of agents consume the same amount at time 2 even with a non-revealing tax scheme.

We therefore implement the optimal allocation with a truth-telling tax scheme. Both agents and the government at time 1 rationally expect that the government at time 2, observing the tax payments $t_{1 s}$ and the level of savings $k_{s}$ of each agent and taking as given the predetermined tax scheme $t_{1 s}$ and $\mathcal{T}_{s}$, chooses $\left(t_{2 s}\right)_{s=H, L}$ to maximize

$$
\sum_{s=H, L} \pi_{s} u\left(c_{2 s}\right)
$$

subject only to the agents' budget constraints

$$
c_{2 s}=R k_{s}-t_{2 s}, \quad s=H, L,
$$

and the government's budget constraint

$$
\sum_{s=H, L} \pi_{s} t_{2 s}=-R\left(\sum_{s=H, L} \pi_{s}\left(t_{1 s}+\mathcal{T}_{s}\left(k_{s}\right)\right)\right) .
$$

The solution of this problem consists of a tax scheme for time $2, t_{2 s}\left(k_{s}\right), s=H, L$. The crucial effect of lack of commitment, that is, of time inconsistency, is that the tax scheme at time 2 depends on agents' savings choices at time $1, k_{s}, s=H, L$. Recall that, in contrast, with commitment the optimal tax scheme at time 2 consists of simple lump-sum social security payments. It is straightforward to show that $t_{2 s}$ is increasing with $k_{s}$. Indeed, the government provides full insurance at time 2 and all agents consume the same at time 2 . Therefore, the agents' savings decisions at time 1 are distorted: high savings at time 1 lead to the expropriation of accumulated savings at time 2. In fact, given that savings get expropriated ex-post, agents effectively take their consumption at time 2 as given and as independent of the amount that they save. But then agents do not have an incentive to save at all at time 1 . The government will have to take that into account at time 1 and provide agents with tax incentives to save as we will see. More formally, an agent with income shock $\theta_{1 s}, s=H, L$, 
at time 1 , and facing tax schedules $\left(t_{1 s}, t_{2 s}, \mathcal{T}_{s}\right)_{s=H, L}$ solves the following problem at time 1:

$$
\max _{\left(k_{s}, c_{1 s}, c_{2 s}, \hat{s}\right)} \sum_{t=1}^{2} \beta^{t-1} u\left(c_{t s}\right)
$$

subject to

$$
c_{1 s}=\theta_{1 s}-t_{1 \hat{s}}-k_{s}-\mathcal{T}_{\hat{s}}\left(k_{s}\right), \quad c_{2 s}=R k_{s}-t_{2 \hat{s}}\left(k_{s}\right),
$$

where $\hat{s} \in\{H, L\}$. The government's optimal taxation problem at time 1 is then to choose $\left(t_{1 s}, \mathcal{T}_{s}\right)_{s=H, L}$ to maximize the ex-ante expected utility of the representative agent,

$$
\sum_{t=1}^{2} \beta^{t-1} \sum_{s=H, L} \pi_{s} u\left(c_{t s}\right),
$$

subject to the constraint that $\left(k_{s}, c_{1 s}, c_{2 s}, s\right)$ solves the agent's problem (14-15) given $\left(t_{1 s}, t_{2 s}, \mathcal{T}_{s}\right)_{s=H, L}$, for $s=H, L$, and the constraint that $\left(t_{2 s}\right)_{s=H, L}$ solves the time 2 government's problem (11-13) given $\left(t_{1 s}, \mathcal{T}_{s}\right)_{s=H, L}$, where we can omit the government's intertemporal budget constraint since it is satisfied by the tax scheme chosen by the government at time 2 . The government at time 1 anticipates affecting the tax scheme that will be chosen at time 2 through the effect of taxes at time 1 on the savings levels $k_{s}, s=H, L$, and through the government budget constraint. We can now complete the characterization of the optimal truth-telling tax scheme, as stated in Proposition 4. In particular, at time 1 both the agents and the government will anticipate that $\left(t_{2 s}\right)_{s=H, L}$ will be chosen at time 2 to provide full insurance across agents' types, as implied by the solution of problem (11-13). In turn, full insurance at time $2, c_{2 H}=c_{2 L}$, greatly reduces agents' incentives to save; since agents' retirement consumption is independent of their individual savings, they have no incentive to save at all. As a result, the government has to effectively force agents to save at time 1 . To do so, the government chooses taxes on savings at time 1 such that $\mathcal{T}_{s}^{\prime}(k)=\tau_{s}^{-}=-1$, for $k \leq k_{s}$, and $\mathcal{T}_{s}^{\prime}(k)=\tau_{s}^{+}=0$ otherwise. Thus, if an agent were to save less than $k_{s}$, he would incur taxes in the amount of the difference between his savings and $k_{s}$. Alternatively, we can interpret this as a subsidy for savings up to $k_{s}$ and saving anything less than $k_{s}$ results in a loss of the subsidy. Given these taxes on capital, agents of both income levels are willing to save $k_{s}$. Agents with low income will not save less than $k_{L}$ because this would raise their taxes at time 1 one-for-one. We can interpret this as agents not being able to borrow against their retirement income. Agents with high income will not save more that $k_{H}$ since additional savings would be expropriated by the government at time 2 . Recall that $k_{H}=k_{L}$ and thus the capital tax schedule is the same for both types of agents and agents have no incentive to misreport their income. In this way, we are able to implement the optimal incentive compatible allocation which satisfies $c_{1 H}>c_{2 H}=c_{2 L}>c_{1 L}$. To sum up, because the government cannot commit not to expropriate agents who save ex-post or bail agents who do not save out, agents have no incentive to save at all, and 
the government needs to force agents to save ex-ante (or keep them from borrowing against social security benefits).

\subsection{Optimal fiscal policy and anonymous markets}

Suppose the government can give agents unrestricted access to anonymous markets, where it cannot monitor their savings. That is, suppose agents can save an amount $k_{s}, s=H, L$, of their choice, hidden from the government, at the same gross interest rate or return $R=\frac{1}{\beta}$. In this case agents can in effect smooth any state contingent consumption plan offered by the government. We discuss the effects of anonymous unmonitored credit markets in turn for the optimal fiscal policy problem with and without commitment.

When hidden savings are allowed by a government with commitment, the optimal consumption allocation must satisfy the additional constraint that agents will optimally choose not to save more or less than the amount $k_{s}, s=H, L$, using the anonymous markets in order to smooth their allocation, i.e., that additional savings $\hat{k}_{s}, s=H, L$, are zero: $\hat{k}_{H}=\hat{k}_{L}=0$. This amounts to adding the following constraint to the problem in (1-3):

$$
\hat{k}_{s}=0 \in \arg \max _{\tilde{k}_{s}} u\left(c_{1 s}-\tilde{k}_{s}\right)+\beta u\left(c_{2 s}+R \tilde{k}_{s}\right), \quad s=H, L .
$$

Notice that this adds an extra agency problem. Moreover, the solution to the problem in (1-3), the optimal allocation when no access to anonymous markets is allowed, has the property that $c_{1 L} \neq c_{2 L}$, and hence it does not satisfy constraint (17). It is therefore straightforward to show the following:

Proposition 5 It is optimal for a government with commitment not to allow the agents access to anonymous credit markets. At the optimal allocation with commitment and access to anonymous credit markets: i) agents perfectly smooth their consumption: $c_{1 s}=c_{2 s}, s=H, L$; and ii) no social insurance is provided: $c_{1 s}+\frac{1}{R} c_{2 s}=$ $\theta_{1 s}, s=H, L$.

Note that the optimal allocation with commitment and access to anonymous credit markets coincides with the allocation that agents could achieve in an economy where they do not have access to state contingent insurance claims, but only to credit markets where they can borrow and lend at the interest rate factor $R .^{21}$

It is instructive to illustrate the effects of anonymous markets by also looking at the restrictions they impose on the optimal taxation problem which implements the optimal allocation. If agents have access to anonymous markets, agents can hide the capital tax base, and the optimal taxation problem is restricted by $\mathcal{T}_{s}=0$,

\footnotetext{
${ }^{21}$ Environments of this type have been studied, e.g., by Allen (1985) and Cole and Kocherlakota (2001).
} 
$s=H, L$. Agents can perfectly smooth their after tax income, and hence their only concern is the present value of income taxes and social security payments. The only incentive compatible fiscal policies, therefore, are such that income taxes and social security payments are equal in present value for both types of agents (and hence must have present value equal to zero). Indeed, the government cannot provide any social insurance at all and might as well set taxes and social security payments to zero.

Consider now the effects of allowing access to anonymous unmonitored credit markets when the government has no commitment. Suppose the government allows agents not to reveal their income at time 1 and instead recommends that agents save to perfectly smooth their income across the two time periods using anonymous markets. Given that agents do not reveal their income to the government, the government will not know agents' types at time 2 from their reports or tax payments at time 1. Moreover, since agents save in anonymous markets, agents' savings are not observable to the government either and do not reveal agents' types indirectly. Thus, the government at time 2 remains completely uninformed about the agents' types and, given that, will not choose to redistribute any resources. In this way, the lack of commitment government can actually implement the allocation that agents could achieve in an economy where they do not have access to state contingent insurance claims, but only to credit markets where they can borrow and lend at the interest rate factor $R$. Hence, the lack of commitment government does as well as a government with commitment when agents have access to anonymous markets.

Allowing for anonymous markets improves matters for a government which lacks commitment with respect to the case in which the government lacks commitment and savings are observable. In either case, the difference between each agent's income and his consumption at time 1 equals his savings and hence equals the present value of what he consumes at time 2 , which means that the present value of the allocation of each type equals his income, $\theta_{1 s}$. But, with anonymous markets, agents perfectly smooth their consumption and choose different levels of consumption at time 2, i.e., $c_{2 H} \neq c_{2 L}$, and savings decisions for retirement are not distorted. Thus, both types of agents must be better off with anonymous markets.

In terms of the tax scheme implementing the optimal allocation, if the government allows the agents access to anonymous credit markets, this implies that its fiscal policy is subject to the restriction that $\mathcal{T}_{s}=0, s=H, L$, as well as to the additional restriction that the income taxes at time $2, t_{2 s}$, cannot depend on $k_{s}, s=H, L$. As a consequence, when agents have access to anonymous markets, agents with high income may save more without being expropriated by the government ex-post.

Proposition 6 It is optimal for a government without commitment to allow the agents access to anonymous credit markets. At the optimal allocation without commitment and with access to anonymous credit markets: i) agents perfectly smooth their consumption: $c_{1 s}=c_{2 s}, s=H, L$; and ii) no social insurance is provided: $c_{1 s}+\frac{1}{R} c_{2 s}=\theta_{1 s}$. 
Note that the optimal allocation implemented with access to anonymous credit markets is the same whether the government has commitment or not. Also note that at the optimal allocation hidden savings are in fact used in equilibrium at least by agents with high income. In this sense hidden savings are essential to implementing the optimal allocation.

The combination of lack of revelation ex-ante and anonymous markets allows the government to pre-commit not to expropriate agents with high income ex-post. Both the lack of revelation and anonymous markets are critical. If agents were to tell the truth ex-ante, the government would not be able to implement the above allocation, since the time 2 government would know agents' types and hence be able to redistribute despite the fact that agents' assets are hidden. If their savings were not hidden, then lack of revelation would not be sufficient since the savings levels would reveal the information to the government ex-post. ${ }^{22}$

Granting agents unrestricted access to anonymous credit markets restricts capital tax schedules and the history-dependence of income tax schedules. This has positive welfare effects when the government lacks commitment in our economy, for all parameterizations. Recall that in general anonymous markets are welfare improving when the welfare costs of reduced social insurance are smaller than the welfare benefits which can be obtained by eliminating the distortions on savings. But in the economy with hidden information we have studied in this section a government lacking commitment is unable to provide agents with any social insurance. Thus, granting agents access to anonymous markets has the sole effect of reducing the distortions in agents' savings decisions. Moreover, granting agents access to anonymous markets can also be welfare improving when the government without commitment would otherwise provide so much social insurance that agents would no longer have an incentive to exert effort.

We should mention an important caveat to our result that the restrictions that anonymous markets impose on the optimal fiscal policy can have positive welfare effects when the government lacks commitment. Trades in anonymous markets need be enforced by a system which protects property rights, particularly so when such trades are intertemporal as in our context. Our result therefore implicitly assumes that property rights are in general enforced even when the government lacks commitment. In several applications of interest this assumption is not unreasonable: in the case of offshore financial markets, for instance, anonymous intertemporal trades are enforced by the legal and regulatory system of the offshore country (and in the

\footnotetext{
${ }^{22}$ It turns out that an optimal allocation with truth-telling does not exist here. To see this note that if agents tell the truth ex-ante, then the time 2 government will redistribute resources such that $c_{2 H}=c_{2 L}$. This is feasible despite the fact that agents have access to anonymous markets because the government knows agents' types, given that they are telling the truth, and knows their savings $k_{s}$ in equilibrium (although it cannot observe them). However, with access to anonymous markets agents will perfectly smooth their consumption intertemporally and hence $c_{1 s}=c_{2 s}, s=H, L$. But then there is perfect insurance and, given this, agents with high income would not announce their income truthfully since by declaring low income they could pocket the difference.
} 
case of capital mobility from developing countries, by the legal system of the developed countries). More generally, a basic system of property rights protection is often enforced even by countries with limited political and fiscal governance mechanisms.

\section{Optimal fiscal policy with hidden effort}

We briefly discuss several additional example economies with hidden effort in which granting agents access to anonymous markets might be valuable.

\subsection{Hidden effort}

Consider the same economy as before, except that agents choose an unobservable effort level at time 1 which affects the probability of the high income state at time $1, \theta_{1 H}$, which is now observable. The choice of effort $e \in\left\{e_{0}, e_{1}\right\}$ is associated with a utility cost $v(e)$, with $v\left(e_{0}\right)<v\left(e_{1}\right)$, and with a probability of the high income state $\pi_{H}(e)$, with $\pi_{H}\left(e_{1}\right)>\pi_{H}\left(e_{0}\right)$. We interpret the representative agent's effort choice as affecting the probability that the agent is highly skilled, i.e., as affecting the accumulation of human capital. The government chooses taxation to provide social insurance wary of the effects of the tax scheme on the representative agent's human capital accumulation. ${ }^{23}$

Consider first a government with commitment. We proceed as in the section before, by first studying the optimal allocation and then its tax implementation. The government chooses an allocation $\left(c_{1 s}, c_{2 s}\right)_{s=H, L}$ to maximize

$$
\sum_{t=1}^{2} \beta^{t-1} \sum_{s=H, L} \pi_{s}\left(e_{1}\right) u\left(c_{t s}\right)-v\left(e_{1}\right)
$$

subject to the incentive compatibility constraint

$$
\sum_{t=1}^{2} \beta^{t-1} \sum_{s=H, L} \pi_{s}\left(e_{1}\right) u\left(c_{t s}\right)-v\left(e_{1}\right) \geq \sum_{t=1}^{2} \beta^{t-1} \sum_{s=H, L} \pi_{s}\left(e_{0}\right) u\left(c_{t s}\right)-v\left(e_{0}\right),
$$

and the budget constraint

$$
\sum_{s=H, L} \pi_{s}\left(e_{1}\right) c_{1 s}+\frac{1}{R} \sum_{s=H, L} \pi_{s}\left(e_{1}\right) c_{2 s}=\sum_{s=H, L} \pi_{s}\left(e_{1}\right) \theta_{1 s} .
$$

Note that we are assuming that implementing high effort, i.e., $e_{1}$, is optimal.

At the optimal allocation with commitment, consumption is perfectly smoothed conditional on each agents' income at time 1, i.e., $c_{1 H}=c_{2 H}$ and $c_{1 L}=c_{2 L}$. In terms

\footnotetext{
${ }^{23}$ The logical steps of the analysis in this case and the subsequent ones follow those of the previous hidden income economy. We are therefore less formal about the presentation of the various optimal taxation problems.
} 
of capital taxation, this implies that capital is not taxed when the government has commitment, i.e., $\tau_{s}=0, s=H, L$. To induce the agent to invest in human capital, that is, to exert effort $e_{1}$, the government provides less than full social insurance, however, i.e., $c_{1 H}=c_{2 H}>c_{1 L}=c_{2 L}$. Optimal income taxes $t_{1 s}$ at time 1 are higher for high income agents than for low income agents and the present value of income taxes net of social security payments is negative for high income agents and positive for low income agents.

Because consumption is smoothed perfectly, this allocation can still be implemented when agents have access to hidden savings. Thus, with commitment, the government is indifferent regarding the agents' access to anonymous credit markets.

Consider instead the case without commitment. As in the previous section we study the optimal allocation with truth-telling, check that it is not dominated by an allocation supported by a non-revealing mechanism, and finally study its tax implementation. Suppose the government implements a mechanism with truth-telling. In this case, again, the government is unable to keep itself from reneging on its promises at time 2 and provides full insurance ex-post. But since agents rationally expect that the government will implement $c_{2 H}=c_{2 L}$ at time 2, all incentives to induce effort $e_{1}$ have to be provided through the allocation at time 1 , i.e., through $c_{1 s}, s=H, L$. Assuming that it remains optimal to induce high effort, the optimal allocation satisfies $c_{1 H}>c_{2 H}=c_{2 L}>c_{1 L}$, and income taxes are chosen accordingly. ${ }^{24}$ Note that the consumption allocation of neither type is characterized by perfect smoothing. This is because lack of commitment results in taxation at time 2 that effectively depends on $k_{s}$, and hence the net (after-tax) rate of return on savings implicitly depends on the state $s$. In other words, agents with high income cannot save more since the government would expropriate them ex-post. Moreover, since the government would bail agents out who do not save, it has to provide agents with tax incentives to save ex-ante (or, equivalently, keep agents from borrowing against social security income).

The character of the optimal allocation with lack of commitment is not changed when we consider non-revealing mechanisms (or randomized reporting strategies for that matter). If the government considers a non-revealing mechanism, this implies that agents consume the same amount at time 2 in equilibrium. Otherwise, if agents would save different amounts and thus indirectly reveal their types, for example, the government would redistribute resources ex-post. But then the government would be unable to implement an allocation which dominates the one in a truth-telling mechanism.

Finally, we study the case in which the government which lacks commitment gives agents access to anonymous credit markets. Consider again a non-revealing mechanism, i.e., taxes at time $1, t_{1 s}$, which are independent of $s$. The time 2 government, which observes taxes at time 1 , will then not be able to infer agents' types. Notice

\footnotetext{
${ }^{24}$ It may be the case that it is no longer optimal to induce high effort when the government lacks commitment. But this would not change our conclusion regarding the value of giving agents access to anonymous markets.
} 
that we assume that despite the fact that the income of agents in this economy is observable to the government at time 1, the time 2 government can only observe agents' types through agents' reports or taxes at time 1, i.e., only if the time 1 government requires agents to report their income in order to make taxes dependent on it. $^{25}$ Thus, the government remains uninformed by time 1 income taxes. Moreover, if agents save using the anonymous markets, the time 2 government cannot observe savings either and, not knowing agents' types, will hence refrain from redistributive income taxation. This however means that the government does not provide any social insurance. Now, for an open set of parameters, the expected utility of the representative agent is higher when he can perfectly smooth consumption conditional on the income realization in the absence of any social insurance, than when the retirement savings decision is distorted as in the case in which access to hidden savings is restricted. To see this, suppose the parameters $\theta_{1 H}$ and $\theta_{1 L}$ are such that with commitment the optimal allocation coincides with the allocation which agents could achieve in an economy where they do not have access to state contingent insurance claims, but only to credit markets where they can borrow and lend at the interest rate factor $R$, i.e., $c_{t s}=\theta_{1 s} R /(1+R)$ for $s=H, L$, and $t=1,2$. Then this is also the solution with anonymous markets. The lack of commitment solution with no access to anonymous credit markets requires $c_{2 H}=c_{2 L}$ and is hence clearly worse. The same is true in a small enough neighborhood of such values of $\left(\theta_{1 s}\right)_{s=H, L}$.

Thus, we conclude that, for an open set of parameters, a government without commitment strictly prefers to give agents access to anonymous credit markets. The government without commitment, however, does not do as well as a commitment government by allowing access to hidden savings. While hidden savings constrain the government ex-post, which is valuable since the government lacks commitment, lack of commitment remains a constraint as it limits the amount of social insurance that the government can provide the agents with.

In order to clarify the intuition behind this result, we compute the optimal allocation as well as the ex-ante expected utility of the representative agent in the different fiscal policy regimes for an example economy. The parameters of the numerical example are summarized in Panel A of Table 1. The values for the optimal allocations and the resulting expected utilities are reported in Panel B. The government with commitment provides some insurance and smoothes the consumption of each type of agent perfectly intertemporally, and this is the case with or without access to anonymous markets (see the first and second rows of Panel B). When the government lacks commitment and agents do not have access to anonymous markets, both types of agents consume the same at time 2 , and thus the government can provide only limited insurance at time 1 to maintain agents' incentives to exert high effort (see the last row of Panel B). Without commitment, but with access to anonymous markets, agents

\footnotetext{
${ }^{25}$ However, we consider the case in which both effort and income are private information below, which allows us to drop this assumption and leads to qualitatively similar results.
} 
can perfectly smooth their income intertemporally. However, the government cannot provide any insurance at all. Nevertheless, the utility attained with access to markets exceeds the utility attained without such access (see the third row of Panel B). The gains that access to markets entail from perfect intertemporal smoothing exceed the cost in terms of loss of insurance in our example. This is not necessarily the case, however. With different parameter values, the gains from intertemporal smoothing could very well be lower than the cost due to the loss of insurance. Indeed, this is the case with enough risk in the economy.

We can illustrate this basic intuition in our numerical example. A mean preserving spread of income, for instance, does not affect the commitment solution nor does it affect the solution without commitment when agents do not have access to anonymous markets (since only the expected income, $\sum_{s=H, L} \pi_{s}\left(e_{1}\right) \theta_{1 s}$, affects the mechanism design problem in these cases). In contrast, when the lack of commitment government allows agents access to anonymous markets, agents are not insured and thus their utility is reduced under a mean preserving spread of income. If the high income is raised to $\theta_{1 H}=2$ and the low income lowered to $\theta_{1 L}=1$, for example, the utility without commitment and with access to markets decreases to -0.9297 , which is less than the utility without access to markets. In this case markets allow intertemporal smoothing but the price in terms of lost insurance is too high.

Thus far we have assumed that income at time 1 is observable to the government, but the time 2 government can only observe agents' types through agents' reports or taxes at time 1 . This simplifies the analysis, but our results are not predicated on this assumption. Indeed, we obtain similar results when assuming that not only effort, but also income, is unobservable. The government's problem then needs to consider both the incentives to exert effort as well as the incentives to announce the income ex-post. The results for a numerical example with hidden effort and hidden income, for the same parameter values, are reported in Panel C of Table 1.

In this case, the commitment government has to provide agents with high income at time 1 with incentives to announce their income truthfully. This constraint binds and results in a distortion of the optimal allocation (see the first row of Panel $\mathrm{C}$ ). Moreover, with hidden effort and hidden income, access to anonymous markets makes it impossible for the government to insure agents while providing agents with incentives to announce their income truthfully. Therefore the government with commitment strictly prefers not to give agents access to anonymous markets (see the second row of Panel C). Different from the economy with hidden effort and observable income, the government without commitment can do as well as the government with commitment by giving agents access to anonymous markets (see the third row of Panel C). Finally, the government with no commitment which prevents agents from accessing anonymous markets treats all agents the same at time 2 and hence cannot provide any insurance at time 1: the difference between the consumption of agents with high income and agents with low income must equal the difference in their 
income in this case (see the last row of Panel C). This introduces a considerable distortion into the allocation, and thus the government without commitment does much better by giving agents access to anonymous markets.

There are two additional ways in which a government that lacks commitment might be able to improve on the allocations it is able to offer and which are of interest in practice. First, if hidden savings are not just hidden and hence not observable but moreover cannot be seized by the government ex-post, the government would be able to implement the commitment solution. Second, if the time 1 government could implement "limited record-keeping," which means that not all the information collected to enforce taxation at time 1 is available to the time 2 government, then the commitment allocation could again be implemented if hidden savings are available. We discuss these in turn.

The role of non-seizable hidden savings. Consider our basic economy with hidden effort (and observable income). Suppose hidden savings are not seizable by the government ex-post, meaning that the government cannot get agents to give up hidden savings, but only observable savings. This changes the constraint imposed by lack of commitment as follows: the time 2 allocation $\left(c_{2 H}, c_{2 L}\right)$ which the government promises to agents at time 1 satisfies

$$
\left(c_{2 H}, c_{2 L}\right) \in \arg \max _{\hat{c}_{2 H}, \hat{c}_{2 L}} \sum_{s=H, L} \pi_{s} u\left(\hat{c}_{2 s}\right),
$$

subject to $\sum_{s=H, L} \pi_{s} \hat{c}_{2 s} \leq \sum_{s=H, L} \pi_{s} c_{2 s}$ as well as

$$
\hat{c}_{s} \geq R k_{s}, \quad s=H, L .
$$

where $k_{s}, s=H, L$ are the hidden savings of agent $H$ and $L$, respectively. Importantly, the time 2 government cannot reduce the allocation of any agent below the amount in the hidden savings account. Clearly, this is an additional way in which hidden savings might restrict the time-inconsistency problem of the government and might improve matters further. Indeed, the commitment allocation can now be implemented as follows: Agents pay taxes at time 1 as in the commitment solution and save the amount required to fund their retirement consumption using hidden savings. This implements the commitment allocation as long as the time 2 government does not redistribute resources. The time 2 government knows agents' types from their tax reports at time 1 , but since it cannot seize the hidden savings, it cannot provide extra insurance ex-post. Thus, the time-inconsistency problem can be completely overcome in this example with non-seizable hidden savings.

The role of limited record keeping. The idea of limited record keeping is that the government at time 1 can destroy information that is solicited by the government at time 1 to implement taxation so that it is not available to the government at time 2 . 
As above, we can implement the commitment solution by imposing the corresponding time 1 taxes, asking agents to save using the hidden accounts, and choosing not to pass along the records from time 1 taxation to the time 2 government. The time 2 government remains uninformed, since it does not have the time 1 records and cannot see savings, and hence will not be able to implement further redistribution. Limited record-keeping can hence play a role as a commitment device similar to the one played by (otherwise inefficient) lags in the political decision making process. ${ }^{26}$

While non-seizable hidden savings and limited record keeping can be valuable when the government lacks commitment, neither would be of value and indeed they might be a constraint for a commitment government.

\subsection{A Mirrlees economy}

Consider a variation of the previous environment in which agents' labor productivity and their labor supply are not observable, while their income is observable. This is a version of the economy originally studied by Mirrlees (1971) and recently by Albanesi and Sleet (2004) and Kocherlakota (2004a), who consider the case in which the government has commitment. ${ }^{27}$ Agents' labor productivity at time 1 is stochastic and is high, $\theta_{1 H}$, with probability $\pi_{H}$ and low, $\theta_{1 L}$, otherwise. Agents' preferences are separable in consumption and labor, i.e.,

$$
\sum_{t=1}^{2} \beta^{t-1} \sum_{s=H, L} \pi_{s} u\left(c_{t s}\right)-\sum_{s=H, L} \pi_{s} v\left(l_{1 s}\right)
$$

where $l_{1 s}$ is the amount of labor supplied given realized labor productivity $\theta_{1 s}$. One interpretation of this environment is that while the number of hours agents work may be observable, how hard they work while at work is not.

The government's problem is to choose an allocation $\left(c_{1 s}, c_{2 s}, l_{1 s}\right)_{s=H, L}$ to maximize agents' ex-ante expected utility (23) subject to the incentive constraint

$$
u\left(c_{1 H}\right)-v\left(l_{1 H}\right)+\beta u\left(c_{2 H}\right) \geq u\left(c_{1 L}\right)-v\left(\frac{\theta_{1 L}}{\theta_{1 H}} l_{1 L}\right)+\beta u\left(c_{2 L}\right),
$$

and the government's budget constraint

$$
\sum_{s=H, L} \pi_{s} c_{1 s}+\frac{1}{R} \sum_{s=H, L} \pi_{s} c_{2 s} \leq \sum_{s=H, L} \pi_{s} \theta_{1 s} l_{1 s}
$$

The incentive constraint requires that agents with high labor productivity prefer to announce their productivity rather than adjust their labor supply and pretend that

\footnotetext{
${ }^{26}$ See Chari (2000).

${ }^{27}$ We thank an anonymous referee for encouraging us to analyze this example.
} 
their productivity realization is low. (The incentive compatibility constraint for the low productivity agents is again not binding and has hence been dropped.) Notice that in the resource constraint labor is multiplied by its productivity. Also, as in Section 4.1, we assume that when the government does not make taxes contingent on income at time 1 , the time 2 government does not learn agents' income realizations.

The analysis and conclusions for this environment are closely analogous to the results for the hidden effort economy. Indeed, we can compute an example similar to the one above. The parameters of the example economy are reported in Panel A of Table 2. The government with commitment provides some insurance and perfect intertemporal smoothing of consumption given an agent's productivity, but does not distort the marginal rate of substitution between consumption and labor for productive agents such that $u^{\prime}\left(c_{1 H}\right) / v^{\prime}\left(l_{1 H}\right)=1 / \theta_{H}$. Compared to an environment with no insurance, productive agents consume less and work more. On the other hand, $u^{\prime}\left(c_{1 L}\right) / v^{\prime}\left(l_{1 L}\right)>1 / \theta_{L}$, i.e., the marginal rate of substitution is distorted for agents with low productivity. Moreover, the allocation does not depend on whether agents have access to markets or not (see the first and second row of Panel B of Table 2). In contrast, the government which lacks commitment prefers to give agents access to markets (see the third and fourth row of Panel B of Table 2). When the government lacks commitment and agents have access to markets, both agents work the same amount and $u^{\prime}\left(c_{1 s}\right) / v^{\prime}\left(l_{1 s}\right)=1 / \theta_{s}$, for $s=H, L$. Interestingly, note that, when agents facing a government without commitment have no access to markets, the more productive agents actually work less than the less productive agents at the optimal allocation. Again, the marginal rate of substitution of productive agents is undistorted and, since productive agents consume more at time 1 , they also work less than in the other cases. Lack of commitment implies considerable distortions in this economy!

\subsection{Hidden effort and ex-post markets}

Consider now an economy with hidden effort in which the representative agent receives stochastic income both at time $1, \theta_{1 s}, s=H, L$, and at time $2, \theta_{2 s}, s=H, L$. The effort level chosen by agents at time 1 affects the probability of the high income state, that is, the probability that the agent's income is $\theta_{t H}$ at both time 1 and 2 . Income is therefore persistent. There is no savings technology in this economy and hence there are no savings. Effort $e \in\left\{e_{0}, e_{1}\right\}$ is associated with a cost $v(e)$, with $v\left(e_{0}\right)<v\left(e_{1}\right)$, and the probability of high income is $\pi_{H}(e)$ with $\pi_{H}\left(e_{1}\right)>\pi_{H}\left(e_{0}\right)$. We interpret the representative agent's effort choice as effort towards the success of an entrepreneurial venture. Since there are no savings in the economy, the government's tax scheme consists of only income taxes at time 1 and $2, t_{t s}$. It is chosen to provide the representative agent with social insurance. We will consider whether the government should allow "international" capital mobility, that is, unrestricted access to anonymous capital markets ex-post, so that agents can take their ventures 
somewhere else. We show that this may be valuable in disciplining a government which lacks commitment. ${ }^{28}$

We assume that $\theta_{1 H}>\theta_{2 H} \geq \theta_{2 L}>\theta_{1 L}$ and that

$$
\sum_{s=H, L} \pi_{s}\left(e_{1}\right) \theta_{1 s}=\sum_{s=H, L} \pi_{s}\left(e_{1}\right) \theta_{2 s}
$$

that is, the expected income is the same at time 1 and 2 , but income risk is higher at time 1 .

The government's problem with commitment is quite similar to the one in Section 4.1. The government chooses an allocation $\left(c_{1 s}, c_{2 s}\right)_{s=H, L}$ to maximize the ex-ante expected utility of the representative agent, (18), subject to the incentive compatibility constraint, (19), but now facing separate time 1 and time 2 budget constraints

$$
\sum_{s=H, L} \pi_{s}\left(e_{1}\right) c_{t s}=\sum_{s=H, L} \pi_{s}\left(e_{1}\right) \theta_{t s}, \quad t=1,2
$$

The optimal allocation, implemented via income taxation, provides partial insurance and induces a consumption allocation with the property that $c_{1 H}=c_{2 H}>c_{1 L}=$ $c_{2 L}$.

Consider allowing access to ex-post markets where entrepreneurs will receive their "marginal product." That is, assume that, at time 2, agents can take their ventures somewhere else and generate their income $\theta_{2 s}$ there, which with competitive ex-post markets means that agents can ensure themselves a consumption of at least their income $\theta_{2 s}$ at time 2. But then the government's problem in (18), (19), and (24), has to further satisfy

$$
u\left(c_{2 s}\right) \geq u\left(\theta_{2 s}\right), \quad s=H, L .
$$

When agents have access to ex-post markets, the government's tax scheme cannot support any insurance at date 2 and $c_{2 s}=\theta_{2 s}, s=H, L$. As a consequence, with commitment, the government strictly prefers to limit capital mobility, that is, not to allow access to ex-post markets. ${ }^{29}$

Consider the problem without commitment under truth-telling. Once again, the government will not be able to resist providing full insurance at time 2 , and hence $c_{1 H}>c_{2 H}=c_{2 L}>c_{1 L}$. Adopting a non-revealing mechanism, as in the previous economy, cannot improve the problem of the government at time 1 since it does not pre-commit the time 2 government's choice. The income realization $\theta_{2 s}$ is observed by the government at time 2 , and hence it can always choose taxes to provide full

\footnotetext{
${ }^{28}$ Kehoe (1989)'s argument that it may be undesirable for two governments which lack commitment to cooperate on policy has a similar spirit.

${ }^{29}$ Kehoe and Levine (1993)'s environment with limited commitment is related. They show that the agents' limited commitment ability results in debt constraints and hence restricts the set of incentive compatible allocations. This parallels our result for the government with commitment exactly. We show, however, that when the government lacks commitment, it is not a foregone conclusion that agents' limited commitment is indeed a constraint.
} 
insurance. Indeed, a non-revealing mechanism would imply no insurance at time 1 either and thus would, in general, do worse than a truth-telling mechanism (and so would mechanisms allowing for randomized reporting strategies).

Access to ex-post anonymous markets, on the other hand, implies that the government will not be able to provide insurance at all at time 2. Effectively the lack of commitment constraint (10) is relaxed since the time 2 government can only choose among allocations which satisfy $u\left(\hat{c}_{2 s}\right) \geq u\left(\theta_{2 s}\right), s=H, L$. This helps with incentives to provide effort ex-ante since agents now receive their entire income at time 2 and are no longer expropriated or bailed out, as the case may be. Indeed, depending on parameters a government without commitment may strictly prefer to allow agents to access markets ex-post. (Notice that, with access to ex-post markets, the optimal tax schemes with and without commitment coincide.) To see this, suppose the parameters are such that $\theta_{2 H}$ and $\theta_{2 L}$ coincide with the consumption allocation at time 2 under the commitment solution, i.e., $\theta_{2 s}=c_{2 s}, s=H, L$. With ex-post markets the commitment solution can be implemented. Again, with lack of commitment, the solution does not coincide with this and is hence worse.

Finally, note that, in equilibrium, agents do not actually have to move their projects elsewhere. Rather, agents having unrestricted access to ex-post markets is sufficient.

\subsection{Investment credit}

In this subsection we consider the problem of a government which cannot commit not to "bail out" borrowers whose income is low. We argue that access to hidden risk-free borrowing is welfare improving in this economy, since private lenders in an anonymous market have no incentives to bail borrowers out ex-post, and this has a positive effect on the borrowers' incentives ex-ante. ${ }^{30}$

Consider an economy in which the representative agent receives a stochastic income at time 2 only, $\left\{\theta_{2 H}, \theta_{2 L}\right\}$. The effort level chosen by agents at time 1 affects the probability of the high income state, that is, the probability that the agent's income is $\theta_{2 H}$ at time 2. Effort $e \in\left\{e_{0}, e_{1}\right\}$ is associated with a cost $v(e)$, with $v\left(e_{0}\right)<v\left(e_{1}\right)$, and the probability of high income is $\pi_{H}(e)$ with $\pi_{H}\left(e_{1}\right)>\pi_{H}\left(e_{0}\right)$. At time 1 the representative agent can borrow to finance consumption at the gross interest $R$. At time 1 neither the representative agent nor the government have any information about the future realization of the income of the project, $\theta_{2 s}$. Therefore the government's tax scheme at time 1 consists only of an income tax $t_{1}$ at time 1 and a tax on debt $\tau$, both independent of $s$. The government's tax scheme at time 2 , instead, consists of a state contingent income tax $t_{2 s}$. We can interpret the income tax at time 2 as an investment credit plan.

\footnotetext{
${ }^{30}$ See Bolton and Scharfstein (1996) for a related argument about the commitment value of the presence of multiple creditors.
} 
Consider first a government with commitment. Its optimal policy problem consists of the choice of $\left(c_{1}, c_{2 s}\right)_{s=H, L}$ to maximize

$$
u\left(c_{1}\right)+\beta \sum_{s=H, L} \pi_{s}\left(e_{1}\right) u\left(c_{2 s}\right)-v\left(e_{1}\right)
$$

subject to the incentive compatibility constraint

$$
u\left(c_{1}\right)+\beta \sum_{s=H, L} \pi_{s}\left(e_{1}\right) u\left(c_{2 s}\right)-v\left(e_{1}\right) \geq u\left(c_{1}\right)+\beta \sum_{s=H, L} \pi_{s}\left(e_{0}\right) u\left(c_{2 s}\right)-v\left(e_{0}\right),
$$

and the government's budget constraint

$$
c_{1}+\frac{1}{R} \sum_{s=H, L} \pi_{s}\left(e_{1}\right) c_{2 s}=\sum_{s=H, L} \pi_{s}\left(e_{1}\right) \theta_{2 s} .
$$

Again we assume that effort $e_{1}$ is optimal.

The optimal tax scheme provides partial insurance, and induces a consumption allocation with the property that $c_{2 H}>c_{1}>c_{2 L}$. With commitment, the government strictly prefers not to allow hidden risk-free borrowing. To see this note that the first order conditions of the government's optimal tax problem (26-28) imply

$$
\frac{1}{u^{\prime}\left(c_{1}\right)}=\pi_{H}\left(e_{1}\right) \frac{1}{u^{\prime}\left(c_{2 H}\right)}+\pi_{L}\left(e_{1}\right) \frac{1}{u^{\prime}\left(c_{2 L}\right)}
$$

and thus $u^{\prime}\left(c_{1}\right)<\pi_{H}\left(e_{1}\right) u^{\prime}\left(c_{2 H}\right)+\pi_{L}\left(e_{1}\right) u^{\prime}\left(c_{2 L}\right)$; see Rogerson (1985), Golosov, Kocherlakota, and Tsyvinski (2003), and Kocherlakota (2004b).

Consider now the case without commitment. In this case it is immediate to see that the consumption allocation supported by the optimal tax scheme has the property that $c_{1}=c_{2 H}=c_{2 L}$, and thus the high effort $e_{1}$ cannot be implemented. The time inconsistency of the government's choice, induced by lack of commitment, has the dramatic effect of supporting only tax schemes which provide full insurance. Since the income realization $\theta_{2 s}$ is publicly observed, the government at time 2 can always choose taxes to induce full insurance, and hence it is not possible to limit the time-inconsistency problem here.

Consider instead allowing hidden risk-free borrowing. Implicitly, we are also assuming that if an agent borrows from hidden sources only, the government cannot observe his income. In this case no taxes can be supported, but the high effort $e_{1}$ may be induced in equilibrium. Thus, without commitment, the government again strictly prefers to allow hidden risk-free borrowing depending on parameters.

\section{Conclusions}

We show that access to anonymous markets might be optimal when the government cannot commit. Markets are good even when incentives are an issue - they protect from abuse by the government! 
Importantly, when the government lacks commitment, not requiring the revelation of information about income and anonymous markets may be valuable even if the government is benevolent. Indeed we restrict the analysis in our paper to the case of benevolent governments. But anonymity and anonymous markets are a mechanism to protect agents from the abuse of the government, a fortiori, when governments are not benevolent.

We study optimal income and capital taxation when the government faces a time-inconsistency problem and is unable to commit not to make taxation or social security benefits contingent on agents' accumulated capital or income history. We show that lack of revelation ex-ante and anonymous markets allow the government to pre-commit not to expropriate agents with high income or bail out agents with low income ex-post.

The incentive problem on the part of the principal that we consider is one of lack of commitment. But any incentive problem on the part of the principal could give rise to welfare gains associated with access to anonymous markets. Qualitatively, our results could be extended, for instance, to an economy with double-sided moral hazard. Indeed, our analysis could be extended to general principal-agent environments in which incentive problems or informational asymmetries are two-sided and contracts are incomplete. 


\section{Appendix: A complete characterization of the op- timal tax on capital with commitment and observ- ability of savings}

Suppose the optimal consumption allocation $\left(c_{1 s}, c_{2 s}\right)$ requires the agent to save $k_{s}$. Capital taxes $\mathcal{T}_{s}, s=H, L$, depend on $s$ and $k_{s}$ and let $\mathcal{T}_{s}^{\prime}(k)=\tau_{s}^{+}$if $k>k_{s}$ and $\mathcal{T}_{s}^{\prime}(k)=\tau_{s}^{-}$otherwise. We have shown in the text that, if $\tau_{s}^{+}$and $\tau_{s}^{-}, s=H, L$, are chosen to satisfy

$$
\tau_{s}^{-} \leq 1-\frac{u^{\prime}\left(c_{1 s}\right)}{u^{\prime}\left(c_{2 s}\right)} \leq \tau_{s}^{+}
$$

then agents who choose the tax schedule designed for their income, will indeed save $k_{s}$.

To keep an agent with high income from declaring low income and saving an amount different from $k_{L}, \tau_{L}^{+}$and $\tau_{L}^{-}$need to satisfy

$$
u^{\prime}\left(c_{2 L}\right)\left(1-\tau_{L}^{+}\right) \leq u^{\prime}\left(c_{1 L}+\theta_{1 H}-\theta_{1 L}\right) \leq u^{\prime}\left(c_{2 L}\right)\left(1-\tau_{L}^{-}\right)
$$

Combining equation (29) for $s=L$ and equation (30) we get

$$
\tau_{L}^{-} \leq 1-\frac{u^{\prime}\left(c_{1 L}\right)}{u^{\prime}\left(c_{2 L}\right)} \leq 1-\frac{u^{\prime}\left(c_{1 L}+\theta_{1 H}-\theta_{1 L}\right)}{u^{\prime}\left(c_{2 L}\right)} \leq \tau_{L}^{+} .
$$

Hence, for this equation to be satisfied we must have $\tau_{L}^{+}>0$, i.e., a positive tax on savings above $k_{L}$ is imposed on agents who report low income, whereas we can set $\tau_{L}^{-}=0$. Low income agents face a distorted marginal saving choice at time 1 in order to induce them to consume more at time $1, c_{1 L}>c_{2 L}$. Indeed, $\tau_{L}^{+}$has to be sufficiently high to keep high income agents who declare low income from saving more than $k_{L}$. The higher tax rate $\tau_{L}^{+}>0$ is however not imposed in equilibrium.

Furthermore, we need to consider the savings decision of an agent with low income who declares high income instead. In the direct mechanism we were able to ignore the corresponding incentive constraint, since it does not bind, but this does not imply that in the tax implementation considered the agent could not do better by declaring high income and adjusting savings. The following condition on $\tau_{H}^{+}$and $\tau_{H}^{-}$ are sufficient (but not necessary) to ensure this:

$$
u^{\prime}\left(c_{2 H}\right)\left(1-\tau_{H}^{+}\right) \leq u^{\prime}\left(c_{1 H}+\theta_{1 L}-\theta_{1 H}\right) \leq u^{\prime}\left(c_{2 H}\right)\left(1-\tau_{H}^{-}\right)
$$

which, combined with equation (29) for $s=H$, implies that

$$
\tau_{H}^{-} \leq 1-\frac{u^{\prime}\left(c_{1 H}+\theta_{1 L}-\theta_{1 H}\right)}{u^{\prime}\left(c_{2 H}\right)} \leq 1-\frac{u^{\prime}\left(c_{1 H}\right)}{u^{\prime}\left(c_{2 H}\right)}=0 \leq \tau_{H}^{+} .
$$

Thus, we can set $\tau_{H}^{+}=0$. 
Next we show that we can let $\tau_{H}^{-}=0$ without loss of generality. We know that

$$
u\left(c_{1 H}\right)+\beta u\left(c_{2 H}\right)=u\left(c_{1 L}+\theta_{1 H}-\theta_{1 L}\right)+\beta u\left(c_{2 L}\right)
$$

and

$$
u\left(c_{1 L}\right)+\beta u\left(c_{2 L}\right)>u\left(c_{1 H}+\theta_{1 L}-\theta_{1 H}\right)+\beta u\left(c_{2 H}\right) .
$$

If $\tau_{H}^{-}=0$, then the agent with low income could declare high income and perfectly smooth at interest rate factor $R=\frac{1}{\beta}$. He would thus choose

$$
\max _{\hat{b}} u\left(c_{1 H}+\theta_{1 L}-\theta_{1 H}-\hat{b}\right)+\beta u\left(c_{2 H}+R \hat{b}\right)
$$

which, using the first order condition and $c_{1 H}=c_{2 H} \equiv c_{H}$, can be solved for $b=$ $\frac{1}{1+R}\left(\theta_{1 L}-\theta_{1 H}\right)$ and implies that the agent consumes $\bar{c}_{L} \equiv c_{H}+\frac{R}{1+R}\left(\theta_{1 L}-\theta_{1 H}\right)$. Suppose, by contradiction, that this violates the low type's incentive constraint, i.e.,

$$
u\left(c_{1 L}\right)+\beta u\left(c_{2 L}\right)<u\left(\bar{c}_{L}\right)+\beta u\left(\bar{c}_{L}\right) .
$$

Note that since present value is transferred to agents with low income at an optimal allocation we have that

$$
c_{1 L}+\frac{1}{R} c_{2 L}>c_{1 H}+\theta_{1 L}-\theta_{1 H}+\frac{1}{R} c_{2 H},
$$

such that offering the consumption $\bar{c}_{L}$ at both time 1 and 2 to agents with low income would be cheaper for the government.

Consider hence the alternative allocation $\hat{c}_{t L}=\bar{c}_{L}, t=1,2$, leaving the high type's allocation unchanged. This would be feasible and would make the low type better off. It would also be incentive compatible since

$$
\hat{c}_{1 L}+\theta_{1 H}-\theta_{1 L}+\frac{1}{R} \hat{c}_{2 L}=c_{1 H}+\frac{1}{R} c_{2 H},
$$

i.e., the allocation of the high type under a deviation and when he tells the truth have the same present value and hence

$$
u\left(c_{1 H}\right)+\beta u\left(c_{2 H}\right)>u\left(\hat{c}_{1 L}+\theta_{1 H}-\theta_{1 L}\right)+\beta u\left(\hat{c}_{2 L}\right)
$$

since the allocation when he tells the truth is perfectly smoothed.

But this contradicts optimality of the original allocation. 


\section{References}

Albanesi, S., Sleet, C., 2004. Dynamic optimal taxation with private information. Review of Economic Studies, forthcoming.

Allen, F., 1985. Repeated principal-agent relationships with lending and borrowing. Economics Letters 17, 27-31.

Arnott, R., Stiglitz, J., 1983. Equilibrium in competitive insurance markets with moral hazard. Working Paper.

Berliant, M., Ledyard, J.O., 2004. Optimal dynamic nonlinear income taxes with no commitment. Working Paper, Washington University and California Institute of Technology.

Bester, H., Strausz, R., 2001. Contracting with imperfect commitment and the revelation principle: The single agent case. Econometrica 69, 1077-1098.

Bester, H., Strausz, R., 2003. Contracting with imperfect commitment and noisy communication. Working Paper, Free University Berlin.

Bisin, A., Gottardi, P., 1999. Competitive equilibria with asymmetric information. Journal of Economic Theory 87, 1-48.

Bisin, A., Rampini, A.A., 2006. Exclusive contracts and the institution of bankruptcy. Economic Theory 27, 277-304.

Bolton, P., Scharfstein, D.S., 1996. Optimal debt structure with multiple creditors. Journal of Political Economy 104, 1-26.

Chari, V.V., 2000. Limits of markets and limits of governments: An introduction to a symposium on political economy. Journal of Economic Theory 94, 1-6.

Chari, V.V., Kehoe, P.J., 1990. Sustainable plans. Journal of Political Economy $98,783-802$.

Cole, H.L., Kocherlakota, N.R., 2001. Efficient allocations with hidden income and hidden storage. Review of Economic Studies 68, 523-542.

DeLong, J.B., 2004. Should we still support untrammelled international capital mobility? Or are capital controls less evil than we once believed? The Economists' Voice 1 (1), 1-7.

Edwards, S., 2001. Capital mobility and economic performance: Are emerging economies different? NBER Working Paper 8076. 
Freixas, X., Guesnerie, R., Tirole, J., 1985. Planning under incomplete information and the ratchet effect. Review of Economic Studies 52, 173-192.

Friedman, T.L., 1999. The Lexus and the olive tree. Farrar, Straus Giroux, New York.

Fudenberg, D., Holmström, B., Milgrom, P., 1990. Short-term contracts and longterm agency relationships. Journal of Economic Theory 51, 1-31.

Fuest, C., Huber, B., Mintz, J., 2003. Capital mobility and tax competition: A survey. CESifo Working Paper 956.

Golosov, M., Kocherlakota, N., Tsyvinski, A., 2003. Optimal indirect and capital taxation. Review of Economic Studies 70, 569-587.

Golosov, M., Tsyvinski, A., 2003a. Designing optimal disability insurance. Working Paper, University of Minnesota.

Golosov, M., Tsyvinski, A., 2003b. Optimal taxation with endogenous insurance markets. Working Paper, University of Minnesota and UCLA.

Gourinchas, P.-O., Jeanne, O., 2003. The elusive gains from international financial integration. NBER Working Paper 9684.

Hammond, P.J., 1987. Markets as constraints: Multilateral incentive compatibility in continuum economies. Review of Economic Studies 54, 399-412.

Harris, M., Townsend, R.M., 1981. Resource allocation under asymmetric information. Econometrica 49, 33-69.

Hausmann, R., Velasco, A., 2004. The causes of financial crises: Moral failure versus market failure. Working Paper, Harvard University.

Huber, B., 1999. Tax competition and tax coordination in an optimum income tax model. Journal of Public Economics 71, 441-458.

IMF Background Paper, 2000. Offshore financial centers. Prepared by the Monetary and Exchange Affairs Department, and available at http://www.imf.org/external/np/mae/oshore/2000/eng/back.htm.

Kehoe, P.J., 1989. Policy cooperation among benevolent governments may be undesirable. Review of Economic Studies 56, 289-296

Kocherlakota, N.R., 2004a. Wedges and taxes. American Economic Review 94 (2), 109-113. 
Kocherlakota, N.R., 2004b. Zero expected wealth taxes: A Mirrlees approach to dynamic optimal taxation. Econometrica, forthcoming.

Kydland, F.E., Prescott, E.C., 1977. Rules rather than discretion: The inconsistency of optimal plans. Journal of Political Economy 85, 473-491.

Laffont, J.-J., Tirole, J., 1988. The dynamics of incentive contracts. Econometrica $56,1153-1175$.

Mirrlees, J.A., 1971. An exploration in the theory of optimum income taxation. Review of Economic Studies 38, 175-208.

Myerson, R.B., 1979. Incentive compatibility and the bargaining problem. Econometrica $47,61-73$.

Prescott, E.C., Townsend, R.M., 1984. Pareto optima and competitive equilibria with adverse selection and moral hazard. Econometrica 52, 21-46.

Roberts, K., 1984. The theoretical limits to redistribution. Review of Economic Studies 51, 177-195.

Rogerson, W.P., 1985. Repeated moral hazard. Econometrica 53, 69-76.

Skreta, V., 2002. Sequentially optimal mechanisms. Working Paper, University of Minnesota.

Stokey, N.L., 1989. Reputation and time consistency. American Economic Review 79 (2), 134-139.

Stokey, N.L., 2003. 'Rules versus discretion' after twenty-five years. NBER Macroeconomics Annual 2002. 
Table 1: Numerical example with hidden effort

Panel A: Parameters

\begin{tabular}{|c|c|c|c|c|c|c|c|}
\hline $\begin{array}{c}u(\cdot) \\
\log (\cdot) \\
\end{array}$ & $\begin{array}{c}\beta \\
0.96 \\
\end{array}$ & $\begin{array}{c}\theta_{1 H} \\
1.95 \\
\end{array}$ & $\begin{array}{c}\theta_{1 L} \\
1.05 \\
\end{array}$ & $\begin{array}{l}\left(e_{1}\right) \\
.50 \\
\end{array}$ & $\begin{array}{l}I\left(e_{0}\right) \\
.17\end{array}$ & $\begin{array}{c}v\left(e_{\mathrm{c}}\right. \\
0.0 \\
\end{array}$ & \\
\hline \multicolumn{8}{|c|}{ Panel B: Hidden effort } \\
\hline Commitment & $\begin{array}{r}\text { Acc } \\
\text { ma }\end{array}$ & $\begin{array}{l}\text { cess to } \\
\text { arkets }\end{array}$ & Utility & $c_{1 H}$ & $c_{1 L}$ & $c_{2 H}$ & $c_{2 L}$ \\
\hline Yes & & No & -0.8631 & 0.9341 & 0.5966 & 0.9341 & 0.5966 \\
\hline Yes & & Yes & -0.8631 & 0.9341 & 0.5966 & 0.9341 & 0.5966 \\
\hline No & & Yes & -0.9067 & 0.9949 & 0.5357 & 0.9949 & 0.5357 \\
\hline No & & No & -0.9078 & 1.0815 & 0.4491 & 0.7653 & 0.7653 \\
\hline \multicolumn{8}{|c|}{ Panel C: Hidden effort and hidden income } \\
\hline Commitment & $\begin{array}{r}\text { Acc } \\
\text { ma }\end{array}$ & $\begin{array}{l}\text { cess to } \\
\text { arkets }\end{array}$ & Utility & $c_{1 H}$ & $c_{1 L}$ & $c_{2 H}$ & $c_{2 L}$ \\
\hline Yes & & No & -0.8651 & 0.9331 & 0.6392 & 0.9331 & 0.5540 \\
\hline Yes & & Yes & -0.9067 & 0.9949 & 0.5357 & 0.9949 & 0.5357 \\
\hline No & & Yes & -0.9067 & 0.9949 & 0.5357 & 0.9949 & 0.5357 \\
\hline No & & No & -0.9891 & 1.3282 & 0.4282 & 0.6477 & 0.6477 \\
\hline
\end{tabular}

Table 2: Numerical example of a Mirrlees economy

\begin{tabular}{|c|c|c|c|c|c|c|c|c|}
\hline & & $\begin{array}{l}u(\cdot) \\
\log (\cdot)\end{array}$ & $\begin{array}{lc}(\cdot) & \beta \\
(\cdot)^{2} & 0.96 \\
\end{array}$ & $\begin{array}{c}\theta_{1 H} \\
1.3\end{array}$ & $\begin{array}{c}\pi_{H} \\
0.50\end{array}$ & & & \\
\hline \multicolumn{9}{|c|}{ Panel B: Results } \\
\hline Commitment & $\begin{array}{c}\text { Access to } \\
\text { markets }\end{array}$ & Utility & $c_{1 H}$ & $c_{1 L}$ & $c_{2 H}$ & $c_{2 L}$ & $l_{1 H}$ & $l_{1 L}$ \\
\hline Yes & No & -1.3738 & 0.9127 & 0.7105 & 0.9127 & 0.7105 & 1.4243 & 1.3301 \\
\hline Yes & Yes & -1.3738 & 0.9127 & 0.7105 & 0.9127 & 0.7105 & 1.4243 & 1.3301 \\
\hline No & Yes & -1.3824 & 0.9286 & 0.7143 & 0.9286 & 0.7143 & 1.4000 & 1.4000 \\
\hline No & No & -1.3846 & 0.9518 & 0.6617 & 0.8068 & 0.8068 & 1.3658 & 1.3870 \\
\hline
\end{tabular}

